\title{
Customer Knowledge Transfer in the Open Innovation of IoT Enterprises
}

\author{
Chen Yang \\ School of management \\ Xuzhou Institute of Technology \\ Xuzhou, Jiangsu, China
}

\author{
Lin Jing \\ School of management \\ Xuzhou Institute of Technology \\ Xuzhou, Jiangsu, China
}

\begin{abstract}
The aim of this study was to explain the characteristics of customer knowledge transfer and find the way to enhance the knowledge transfer effect. Open innovation provides abundant external resources for enterprise's innovation. As an important external knowledge resource, customers play an increasingly important role in enterprise innovation. The innovation of IoT industry is in the transition period. In this period, although there is a certain willingness of customers to transfer knowledge to IoT enterprises, appropriate external incentive is necessary. From perspective of the three elements of knowledge transfer ability, customers have heterogeneous market knowledge with high knowledge stickiness. IoT enterprises need to solve the problem of customer knowledge stickiness and improve innovation performance by constructing trust mechanism, designing structured problems and broadening knowledge acquisition channels. Absorptive capacity of IoT enterprises should not be ignored.
\end{abstract}

Keywords-Open innovation; Customer knowledge transfer; Knowledge stickiness; Internet of Things

\section{INTRODUCTION}

In recent years, the Internet of Things (IoT) has developed rapidly. The forecast shows that in 2018, the global market for IoT will exceed $\$ 100$ billion, with annual compound growth rate of more than $31 \%$. In China, the IoT industry has jumped from RMB 170 billion in 2009 to more than RMB 930 billion in 2016. IoT has been written into the 13th five-year national plan. According to the report of "2016 Internet of Things Landscape" released by FirstMark, the field of IoT is rapidly expanding unceasingly with characteristics of platform, cloudization and open sourcing. IoT has become an important part of the ICT ecosystem as it integrating the mobile internet, cloud computing and hadoop. The IoT enterprises need to meet the needs of diverse customers, and realize the docking of different fields, different types of application systems and intelligent devices. A variety of IoT practices need to be adapted to thousands of things for both realizing IT functions and driving business development.

It can be seen that the innovation of enterprises is characterized by high exploration and high creativity. Only relying on the internal resources of the enterprise to carry out innovation will produce high cost and low efficiency. The focus of competition and development of IoT enterprises should revolve around the open innovation in various fields.
Open innovation can provide a wealth of external innovation resources for innovation activities, especially external knowledge sources. Because knowledge is the source of innovations and the key elements of innovation activities, open innovation can meet the higher dependence on the external knowledge input for the innovation of IoT enterprises.

\section{THE IMPORTANCE OF CUSTOMER KNOWLEDGE IN THE OPEN INNOVATION OF IOT}

Since the birth of the IoT industry, it faces the market competition pattern of information symmetry and user centralization. Market orientation is the basic requirement for the survival and development of the enterprises. Meanwhile customers become the most important external cooperative innovation subjects for enterprises. As an important external knowledge resource, customers play the role of product opinion leaders and become increasingly important in enterprise innovation. The competition among enterprises is ultimately the competition for high-quality customer resources. This competition is not only in the consumer market, but also in the acquisition of customer knowledge in the open innovation. As an important resource of enterprises, customer resources are becoming a new source of competitiveness for enterprises.

Firstly, the definition of customer status has changed. For example the co-designer, the customer's innovation participation and customer-enterprise interactive innovation show that the enterprise has been fully realized the importance of customers' knowledge and innovation ability for innovation of enterprises. It has been showed that most new products come from customers' ideas. Frank Piller et al. (2003) [1] believe that open innovation is the process of collecting and integrating information from consumers to innovate, modify and standardize products and services. Fang E (2008) [2] found that customer participation in new product development has a significant impact on innovation performance. Chang (2016) [3] pointed out that customer participation in knowledge sharing activities will greatly improve the success rate of product development. Matthing P et al. (2003) [4] think that potential customers' participation in innovation can help enterprises better understand and grasp customer demand and gain sustainable competitive advantage. Customer-enterprise interactive innovation puts the enterprise and the customers in 
the joint creation scenario of the enterprise-customer cooperation innovation.

Secondly, the customer knowledge belongs to the heterogeneous market knowledge, which is conducive to the improvement of the innovation performance. Enterprises urgently need the tacit knowledge accumulated in the consumption process and the information of customers' demand. Scattered and incomplete market information limits the enterprises' innovative thought. Heterogeneous market knowledge can help enterprises to find potential market demand. As the IoT market is characteristics of high-level market segmentation, Heterogeneous market knowledge can update the knowledge base for enterprises and reduce the uncertainty of external market. Guo Wei (2016) [5] found that market knowledge heterogeneity has a positive influence on enterprise innovation performance, while technical knowledge heterogeneity has an inverted u-shaped effect on enterprise innovation performance. This shows that market knowledge resources from customers and technological knowledge resources from suppliers or other objects have different effects on innovation performance. The costs of acquiring different knowledge resources are also different.

\section{CUSTOMER KNOWLEDGE TRANSFER IN THE OPEN INNOVATION OF IOT ENTERPRISES}

\section{A. Customer Knowledge Transfer Intention}

Knowledge transfer is the process by which knowledge owners transfer knowledge, so that knowledge recipients can obtain and apply it. When knowledge transfer occurs, the knowledge owner gives up the ownership and the advantage of heterogeneity knowledge [6], which leads to the reluctance for knowledge owners to transfer the heterogeneity knowledge. In addition, high knowledge transfer cost is also an obstacle to knowledge transfer. Levin (2004) [7] found that knowledge owners adopt evasive or defensive behaviors to avoid high knowledge transfer costs.

However, from the customer's point of view, there is no obvious obstacle to the willingness of knowledge transfer. Customers' knowledge transfer, especially the knowledge about the market demand, to the IoT enterprises can improve their expectation of the degree of need satisfaction in the future. Once the appropriate external incentives are present, the willingness of knowledge transfer can be well stimulated. For example, based on the trust of the knowledge recipient, customers will make positive expectations for the future products and services which is conducive to improving the willingness of customer knowledge transfer.

\section{B. Customer Knowledge Transfer Ability}

1) The weak ability of customer knowledge transfer

Knowledge transfer ability consists of three elements: understanding the needs of knowledge recipients, ability of knowledge coding and selection of knowledge transfer mode [8]. Even if customers have a strong willingness to transfer knowledge, it may be difficult to effectively form knowledge transfer. Most of the customer needs are complex, subtle and variable. Many customers are unaware of their own needs before they try the products. Another hurdle for consumers' knowledge transfer is to articulate their needs, even if they know exactly what they want. In the development of the IoT industry, there are a lot of cases which belong to the creative marketing of enterprises. Enterprises help customers to turn the subconscious, vague and unclear demands to be clear and realistic. It shows that the customers of the IoT enterprises often do not understand the knowledge demands of the enterprises and they are bad at the ability to encode their own needs. In addition, it is extremely infrequent that the customers create or choose the way of knowledge transfer actively. In the perception of the knowledge transfer cost for customers, the cost of finding and using knowledge transfer mode occupies a significant proportion

2) Enhancing customers' understanding of knowledge needs of knowledge recipients

Due to the low ability of customers' knowledge transfer, IoT enterprises are required to make greater efforts from the knowledge receiving party. In order to increase the knowledge demand of knowledge recipients, the enterprises should make a clear distinction of customer knowledge between explicit knowledge and tacit knowledge.

Enterprises should put forward clear questions to customers directly to get explicit knowledge which is easier to transfer, such as the customer's use of data, products, services evaluation and so on. While for tacit knowledge, the form of dialogue should be more adopted. In the dialogue, customers put forward various suggestions, feedback and ideas. Dialogue is an important source of mutual investment between the participants.

The customer toolbox is an effective way to achieve customer dialogue, which can reduce the cost of acquiring customer knowledge and effectively avoid the fuzzy problem of customer knowledge acquired by enterprises. Enterprises provide customers with the necessary toolkits to meet the needs of customers to design and develop their products themselves. The customer toolbox must allow customers to complete a series of design through the way of trial and error and learning by doing. The toolbox consists of practical and debugged components and modules, information about the capabilities and constraints of the production process. All these can make customers feel free and relax to use the toolbox.

3) Solving the problem of poor customer coding ability through structural problems

The information space model proposed by Boisot (2004) [9] studied the flow and evolution of knowledge in three dimensions of coding, abstraction and diffusion. Fig. 1 shows the information space model. Curve AA' indicates that the higher the degree of information coding and abstraction are, the stronger the diffusivity of information will be. Generally, the difficulty of coding increases with the implicit, complex and fuzzy nature of the transferred knowledge.

Customers of IoT enterprises are weak in capability to encode knowledge. Tacit knowledge, such as common sense experience of products and services, skills, know-how, judgments, intuitions, beliefs and mental models, is especially hard to code. As customers can not be trained in coding, the 
enterprises should start with the structuring of "dialogues". For example, structural questionnaire should be designed and structured problems can also be used in the interviews. IT is helpful for customers to clarify the obscure tacit knowledge and output it by closed options. Through structured guidance, enterprises not only obtain the required knowledge, but also complete certain customer code training.

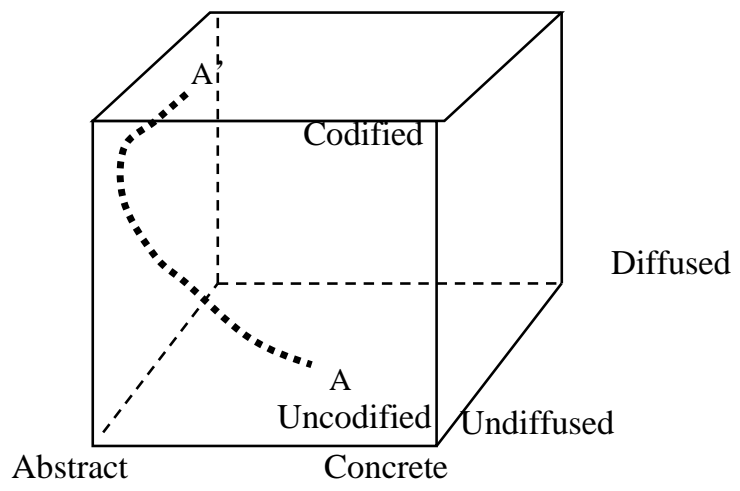

Fig. 1. The Information-Space Model(I-space)

With the development of the industry, the innovation of IoT industry has been entered the transition period. Customers own more and more professional knowledge. Knowledge potential difference formed by the heterogeneous knowledge is more obvious. This is mainly due to the customers' clear understanding of the IoT products and the improvement of the customers' coding capacity [10].

4) Providing more diversified, convenient and low-cost ways for customers to transfer knowledge

Although customers are willing and able to transfer their heterogeneous knowledge, the process of customer knowledge transfer will be terminated if it is difficult to transfer their knowledge easily and efficiently. In general, customers do not transfer their heterogeneous knowledge voluntarily. Enterprises must open up customer knowledge transfer channels and provide abundant and convenient ways that bring the convenience of customers to start the process of knowledge transfer immediately when they are willing to. In order to continuously obtain the advantages of customers' knowledge and resources, enterprises should sustainably improve the interactive modes and broaden the channels of customer knowledge inflow.

The network community is a channel of knowledge transfer worth paying attention to for the IoT enterprises. The network community has become a real gathering place for wide range of visitors with a lot of common interests. It helps the enterprises to reach very accurate customer knowledge sources at low cost. On the other hand, customer knowledge network composed of a large number of units with heterogeneous knowledge will be established because of the frequent communication between customers in the network communities. The interaction between the knowledge network nodes brings about mutual learning among customers. It can not only increase customers' stock of knowledge, but also the spiral of knowledge. Both can lay a firm foundation for the IoT enterprises to acquire more valuable customer knowledge.

\section{Customer KNOWLEDGE STICKINESS}

In the open innovation of IoT enterprises, the majority of heterogeneous market knowledge owned by customers belong to sticky knowledge. Szulanski (1996) listed the difficulty of communication between knowledge sources and knowledge recipients as one of the three major factors leading to the stickiness of knowledge transfer. The I-space model by Boisot also shows that the difficulty of knowledge coding is an important factor in the generation of customer knowledge stickiness. In addition, the intention of knowledge transfer, the lack of incentives and the trust degree of the IoT enterprises will affect the viscosity of knowledge. In a word, there are four causes of the stickiness of knowledge mentioned in many studies as follows: the characteristics of knowledge, the sender of knowledge, the recipient of knowledge and the environment of knowledge transfer. In order to improve the effectiveness of knowledge transfer, IoT enterprises must solve the problem of knowledge stickiness.

As mentioned above, to reduce the customer knowledge stickiness, enterprises should stimulate the motivation and strengthen the intention of customers knowledge transfer. Moreover, the three elements of knowledge transfer ability should be considered to solve the problem of knowledge stickiness. Seeing from another angle, the absorptive capacity of knowledge in the IoT enterprises is an important factor that can not be ignored. The weaker the absorptive capacity of knowledge recipient is, the less knowledge transfer is realized in unit time, and the higher the knowledge stickiness is. Without absorptive capacity, it is difficult to translate knowledge into innovative performance. Absorptive capacity can promote the utilization of knowledge obtained from customers and tap the potential market demands. As a result, enterprises can better identify, transform and use potential market opportunities, and then improve the innovation performance of enterprises.

\section{COUNTERMEASURE AND SUMMARY}

Since the concept of customer innovation has been put forward, open innovation and interactive innovation prevail. Enterprises must pay much attention to the acquisition and utilization of external heterogeneous knowledge resources in order to build long-term competitive advantage through innovation. As an important external knowledge resource, customers play an increasingly important role in enterprise innovation. The acquisition of external heterogeneous market knowledge is beneficial to enterprise innovation and helps enterprises develop new value networks. Acquiring and utilizing customer knowledge can not only make the enterprise clear the direction of enterprise innovation by fully understanding the needs of customers and the market, but also improve the acceptance of innovative products by the market.

As the innovation of IoT industry has been entered in the transition period, the conditions of knowledge interaction for the purpose of heterogeneous knowledge are mature. The most crucial condition is the customer factor. However, in the open innovation of IoT enterprises, the heterogeneous market knowledge owned by customers has a high viscosity. It is required for the enterprises as a knowledge recipient to make 
more proactive strategies to solve the knowledge stickiness problem and improve the effect of customer knowledge transfer. Fig. 2 shows the process and strategy of the IoT enterprises to solve the problem of customer knowledge stickiness and enhance the effect of customer knowledge transfer.

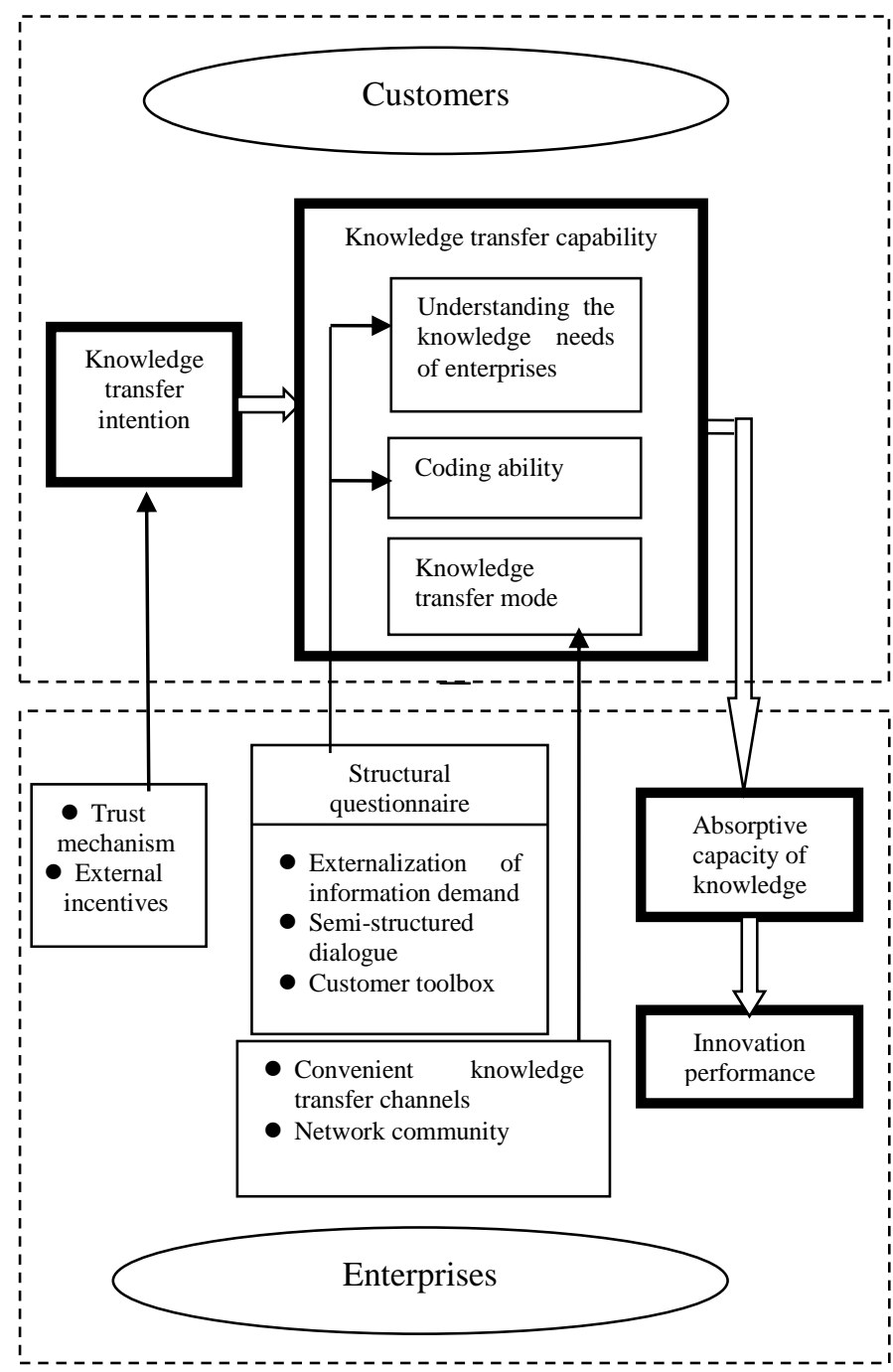

Fig. 2. Innovation performance improvement mechanism based on customer knowledge transfer

Firstly, although there is a certain willingness of customers to transfer knowledge in the transition period of IoT, appropriate external incentive is necessary to turn motivation into action effectively. Trust plays an important role in improving customer knowledge transfer intention. Therefore, enterprises should focus on enabling customers to set up positive expectations for enterprises and their future products. A trust system should be established to promote knowledge transfer.

Secondly, enterprises need to take active measures to improve the knowledge transfer capability of their customers. In view of the fact that it is difficult to effectively carry out the training of the knowledge transfer ability for the customers, the enterprises need to make their own information demands explicit, and guide the customers' knowledge coding. In these two aspects, structuration is a very effective method. Structured problems help customers understand the knowledge content that enterprises want to obtain from customers. Even if the customer can not express the implicit customer knowledge, the semi-structured dialogue can also be adopted. Semi-structured dialogue gives full freedom to customers and clarifies the main content of the dialogue. It is helpful for customers to screen out the knowledge needed by the enterprise. Through structured guidance, the customer's coding is limited to the extent that the enterprise is easy to accept and absorb. Furthermore, enterprises should establish convenient and fast access to getting customers' knowledge. The network community is a channel worthy of attention because the network community can form the customer knowledge network and form the spiral of knowledge by the interaction between network nodes.

Finally, it can not be ignored that absorptive capacity for enterprises plays a major role in promoting customers' knowledge transfer into the innovation performance. Only by strengthening and cultivating the absorptive capacity, can the IoT enterprises promote the efficiency of customer knowledge transfer and knowledge utilization that can finally enhance the innovation performance of enterprises.

\section{REFERENCES}

[1] Piller F T, Schaller C, and Walcher D. "Customers as co-designers: A framework for open innovation", Congress of the International Federation of Scholarly Associations of Management. G teborg: IFSAM, 2004, pp.5-7.

[2] Fang E. "Customer participation and the trade-off between new product innovativeness and speed to market", Journal of Marketing, 4th., vol. 72, 2008, pp. 90-104.

[3] Chang W, Taylor S A. "The effectiveness of customer participation in new product development: a meta -analysis", Journal of Marketing,1st. vol. 80,2016, pp. 47-64.

[4] Matthing P, Matthing J, and Kristenson P. "Managing User Involvement in Service Innovation: Experiments with Innovating End User", Journal of Service Research,2nd. vol.6 2003, pp. 111-123.

[5] Guo Wei. "Knowledge Heterogeneity and Organizational Learning and Innovation Performance of the Company", Science of science and management of S.\&T. 7th. vol. 37. 2016, pp. 118-125. (In Chinese)

[6] Szulanski G. "Exploring internal stickiness: impediments to the transfer of best practice within the firm", Strategic Management Journal,vol.17, 1996,pp. :27-43.

[7] Levin D Z,Corss R. "The strength of weak ties you can trust: the mediating role of trust in effective knowledge transfer", Management Science,11th. vol. 50, 2004, pp.1477-1490.

[8] Mu J,Tang F, Maclachlan D L. "Absorptive and Disseminative Capacity: Knowledge Transfer In Intra- organization net- works”, Expert Systems with Applications, 1st. vol.37, 2010, pp. 31-38.

[9] Boisot, Max.,Canals,Agusti. Data, information and knowledge: have we got it right? Working paper, 2004.

[10] Chen Yang. Jiang Guocheng. "Knowledge synergy in open innovation of IoT industry cluster", E-Business Journal.10th. 2017, pp. 55-56. (In Chinese) 